\title{
ACESSIBILIDADE E UTILIZAÇÃO DOS ESPAÇOS VERDES URBANOS NAS CIDADES DE COIMBRA (PORTUGAL) E SALAMANCA (ESPANHA)
}

\author{
ALEJANDRO GÓMEZ ${ }^{1}$ \\ Cláudia Costa ${ }^{2}$ \\ PAULA SANTANA ${ }^{2}$
}

\begin{abstract}
Resumo - Numa sociedade que valoriza cada vez mais o bem-estar, a saúde e a ocupação dos tempos livres, a oferta de espaços verdes urbanos (EVU) próximos da residência tem-se convertido num direito e numa exigência dos cidadãos. Neste artigo apresenta-se a distribuição e acessibilidade dos EVU nas cidades de Coimbra e Salamanca, é avaliada a frequência e a idade dos utilizadores e, ainda, a motivação e forma de desfrutar esses espaços. Em Coimbra verifica-se concentração e em Salamanca dispersão, com repercussões na sua utilização. De facto, apesar de Coimbra oferecer mais espaço verde urbano por habitante, a utilização é baixa e a deslocação é feita, maioritariamente, de carro, contrariamente ao que é observado em Salamanca. Em consequência os conimbricenses escolhem os EVU pelas actividades que aí poderão realizar e os salmantinos pela proximidade.
\end{abstract}

Palavras-chave: Espaços verdes urbanos, espaço urbano, espaço público, utilização de espaço verde, Coimbra, Salamanca.

\begin{abstract}
ACCESSIBILITY AND USE OF URBAN GREEN SPACES IN THE CITIES OF COIMBRA (PoRTUGAL) AND SALAMANCA (SPAIN). In a society that values more and more wellbeing, health and free time, the introduction of urban green spaces (UGS) next to residential areas has become a citizen's right and requirement. This paper analyses the distribution and accessibility of UGS in the cities of Coimbra and Salamanca and evaluates their influence on the needs of the resident populations, in terms of users' age, frequency of usage, as well as of motivation and ways to enjoy the facilities. In Coimbra there is a concentration of UGS, whereas in Salamanca there is a dispersion of such spaces, which has resulted in the different usage that people make of them. In fact, although Coimbra offers more urban green space (per inhabitant), their usage is reduced as people go there mainly
\end{abstract}

Recebido: Novembro 2012. Aceite: Junho 2013.

1 Departamento de Geografia da Universidade de Salamanca. E-mail: algomez@usal.es

2 Centro de Estudos em Geografia e Ordenamento do Território da Universidade de Coimbra. E-mail: claudiampcosta@gmail.com; paulasantana.coimbra@gmail.com 
by car, contrary to what happens in Salamanca. Consequently, Coimbra's inhabitants choose these green spaces because of the activities they can be used for, whereas Salamanca's inhabitants choose them for their proximity.

Keywords: Urban green spaces, urban space, public space, usage of green spaces, Coimbra, Salamanca.

Résumé - ACCESSIBILITÉ ET UTILISATION DES ESPACES VERTS URBAINS DANS LES Villes de Coimbra (Portugal) et De Salamanque (Espagne). Dans une société qui valorise le bien-être, la santé et l'occupation des loisirs, l'offre d'espaces verts urbains (EVU) proches des résidences est devenue un droit et une exigence des citadins. On compare leur distribution à Coimbra et à Salamanque et leur accessibilité pour les habitants des deux villes; on évalue aussi la fréquence des visites, l'âge des usagers, leur motivation et la façon dont ils profitent des EVU. En effet, alors que Coimbra a une plus grande surface d'espace vert par habitant, leur utilisation y est moindre qu'à Salamanque. On note que les habitants de Coimbra choisissent surtout les EVU en fonction des activités qu'ils peuvent y réaliser et ceux de Salamanque en fonction de leur proximité.

Mots-clés: Espaces verts urbains, espace public, utilisation de l'espace vert, Coimbra, Salamanque.

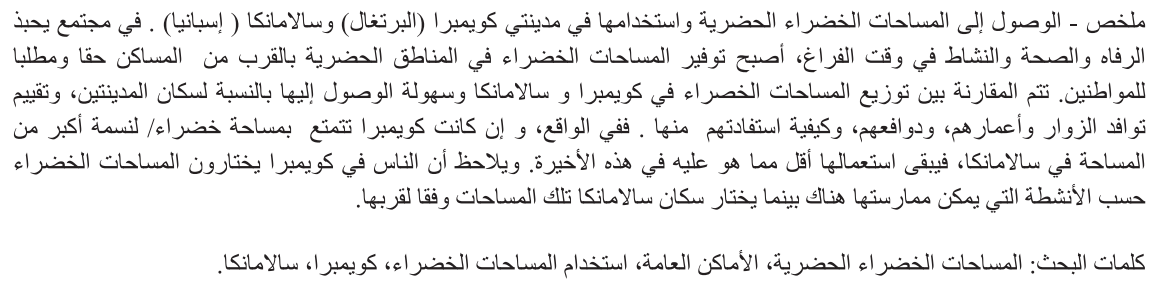

\section{INTRODUÇÃO}

Os espaços verdes urbanos (EVU), mais do que meras funções de embelezamento das cidades, têm outros objectivos, como possibilitar a prática de actividade física e relaxamento, potenciando a coesão social e intergeracional (Pikorta et al., 2003; Humpel et al., 2004; Kim e Kaplan, 2004; Thorsson et al., 2004; Knes e Thorsson, 2006; Tzoulas et al., 2007; Foster et al., 2007; Seeland et al., 2009). A mudança de percepção sobre a utilidade dos EVU aparece em meados do século XX, com a inclusão destes espaços entre as competências do planeamento urbano, e consequente responsabilização pela sua gestão e manutenção, vertida nas competências da administração local (Sanesi e Chiarello, 2006; Fonseca et al., 2010; Madureira et al., 2011; Gómez, 2013).

De facto, numa sociedade em que a população valoriza cada vez mais o bem-estar, a saúde (física e mental) e a ocupação dos tempos livres, a oferta de um espaço verde próximo da residência e do local de trabalho - proporcionando convívio, contacto com a natureza, prática de actividade física, entre outras - é, cada vez mais, um direito, tornando-se, não raras vezes, uma exigência dos cidadãos. No entanto, 
para adequar os EVU às necessidades da população, é necessário conhecer as suas características (localização, dimensão, segurança, limpeza, manutenção, sinalização, equipamentos, adequação à prática de actividades desportivas, etc.), as quais influenciam a utilização e a frequência da utilização, para além de terem importantes impactes no âmbito da saúde pública (Tzoulas et al., 2007; Santana et al., 2007a, 2008, 2010). A literatura científica que identifica os benefícios directos e indirectos dos EVU no ambiente urbano com consequências no bem-estar e na saúde física e mental das populações é vasta. Por exemplo De Vries et al. (2006), Maas et al. (2006) e Santana et al. (2007b) evidenciaram a importância destes espaços na prática de actividade física, no relaxamento e na saúde mental, com impactes no Índice de Massa Corporal, na saúde auto-avaliada e na longevidade. Outros investigadores concluíram que, para além de melhorar a qualidade do ar e atenuar o efeito da poluição e da "ilha de calor urbano" (Whitford et al., 2001; Alcoforado e Andrade, 2007; Vasconcelos e Vieira, 2007; Leal et al., 2008), a utilização desses espaços potencia a capacidade de concentração e disciplina das crianças nas actividades do dia-a-dia, principalmente na população feminina (Taylor et al., 2001), aliviam o stress urbano (Ulrich, 1984; Nielsen e Hansen, 2007) e a fadiga, com consequências na diminuição da agressividade e da violência (Kuo e Sullivan, 2001; Doyle et al., 2006), e influenciam até a capacidade de relacionamento com os vizinhos e os sentimentos de pertença a um lugar (bairro, cidade) (Kim e Kaplan, 2004).

No entanto, nem todos os EVU têm este impacte. Segundo Van Herzele e Wiedemann (2003), a dimensão pode modificar a distância e o tempo que uma pessoa está disposta a percorrer para o alcançar; além disso, a satisfação dos utilizadores depende das oportunidades que cada um oferece. Segundo Magalhães (1992), em Portugal, a Direcção Geral do Ordenamento do Território e Desenvolvimento Urbano (DGOTDU) definiu as distâncias a que os EVU se devem localizar, relativamente à residência, associando o aumento da distância ao aumento da área ${ }^{i}$. É igualmente definido como desejável ou adequado o valor médio de $10 \mathrm{~m}^{2}$ de EVU/habitante na respectiva área de influência (Magalhães, 1992; Santana et al., 2007a, 2010). A acessibilidade geográfica é, de facto, relevante na sua utilização e frequência de uso (Hillsdon et al., 2006; Coombes et al., 2010). Nilsson et al. (1997), referem estudos suecos que demonstraram que, quando a distância a um espaço verde é superior a 300 metros, uma em cada quatro pessoas deixa de o utilizar diariamente.

Coimbra e Salamanca são cidades associadas aos rios que as atravessam e às suas Universidades, as quais, em grande medida, são responsáveis pelo dinamismo dos EVU, como é revelado por alguns autores (Ganho, 1996; Rochette, 2004; Leal et al., 2008; Pêgo et al, 2010). Contudo, em nenhuma das duas cidades há estudos que avaliem a utilização, frequência e percepção dos utilizadores.

No presente artigo apresenta-se a distribuição dos EVU públicos e a sua maior ou menor adequação às necessidades da população, comparando as cidades de Coimbra e Salamanca. Avalia-se a acessibilidade geográfica, o tipo, a frequência e os motivos de utilização e, ainda, de que forma a administração local tem respondido às novas exigências dos cidadãos. 


\section{COIMBRA E SALAMANCA: ENQUADRAMENTO}

Coimbra e Salamanca são duas cidades semelhantes na sua génese: situadas na metade ocidental da Península Ibérica (Coimbra, na região Centro de Portugal; Salamanca, na Comunidade Autónoma de Castela e Leão), são atravessadas por rios, ambos com direcção este-oeste e possuem as universidades mais antigas de cada País (fig. 1). Tanto a Universidade de Coimbra como a de Salamanca alavancam a actividade económica e social das cidades em que se inserem, para além de atraírem uma população estudantil relevante, com impactes na morfologia urbana. A Universidade de Coimbra tinha 21510 alunos inscritos no ano lectivo 2009/2010 (UC, 2010) e a de Salamanca 26251 no ano lectivo 2010/2011 (USAL, 2011) ${ }^{\mathrm{ii}}$.

Apesar de serem cidades históricas, os indicadores geo-demográficos são distintos: em Coimbra residem 98.197 habitantes (INE-PT, 2011), numa área de 5870 ha e em Salamanca 153472 pessoas (INE-ES, 2011) que ocupam 1463 ha, sendo as densidades populacionais, respectivamente de $1672 \mathrm{hab} / \mathrm{km}^{2} \mathrm{e}$ de $10490 \mathrm{hab} / \mathrm{km}^{2}$. A forte concentração da população em Salamanca traduz-se numa densidade que é 6 vezes superior à de Coimbra.

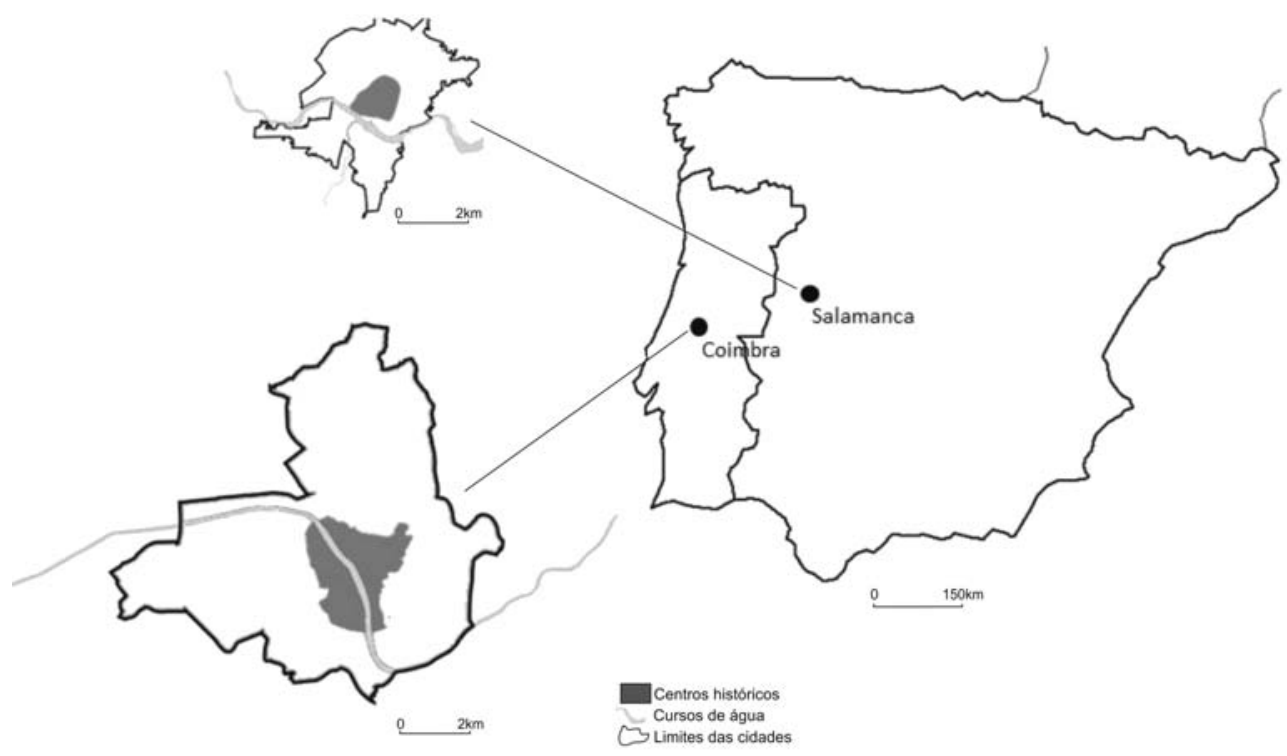

Fig. 1 - Localização e limites das cidades de Salamanca e de Coimbra na Península Ibérica. Fig. 1 - Location and limits of the cities of Salamanca and Coimbra in the Iberian Peninsula. Fonte: Elaborado a partir de cartografia do Instituto Tecnológico Agrario de Castilla y León (Salamanca) e do Gabinete de Informação Geográfica da Câmara Municipal de Coimbra (2007)

A tabela I destaca alguns indicadores das duas cidades. 
Quadro I - Principais indicadores para caracterizar os espaços verdes urbanos (EVU) das cidades de Coimbra e Salamanca.

Table I-Main indicators of the cities of Coimbra and Salamanca.

\begin{tabular}{lcc}
\hline Indicadores & Coimbra & Salamanca \\
\hline Habitantes & 98197 & 153472 \\
População residente no centro histórico & 18471 & 17063 \\
Superfície da cidade (ha) & 5870 & 1463 \\
Densidade populacional (hab/ km²) & 167290 & 1049020 \\
Estudantes na Universidade (aprox.) & 20271 & 30446 \\
$\mathrm{~N}^{\circ}$ espaços verdes urbanos & 9 & 26 \\
EVU (ha) & 105,1 & 100 \\
EVU por habitante (m²/hab) & 10,7 & 6,4 \\
\% da população com acessibilidade a EVU & 21,7 & 82,6 \\
População sem acessibilidade a EVU & 62341 & 23991 \\
\hline
\end{tabular}

Fonte: INE (Portugal), INE (Espanha), UC e USAL (dados de 2011)

$\mathrm{O}$ conceito de espaço verde urbano $\mathrm{iii}^{\mathrm{ii}}$ e de dimensionamento ${ }^{\mathrm{iv}}$ requerido pelos instrumentos de gestão do território são distintos nos países em estudo. O mesmo se verifica quando se analisa a política local para os EVU.

Em Coimbra encontram-se em vigor dois instrumentos de gestão territorial que norteiam o papel dos EVU na cidade: o Plano Director Municipal (PDM) - plano da 1. ' geração aprovado em 1994 - e o Plano Estratégico da Cidade de Coimbra (PEC), aprovado pela Assembleia Municipal em 2010. Apesar do hiato existente entre ambos, as áreas de intervenção e a política relativa a eles são semelhantes: a concentração de grandes EVU junto ao rio e o aproveitamento de áreas marginais ou residuais, situados em zonas de vale, adjacentes a linhas de água, para construção de corredores verdes. O PEC indica que os EVU de pequena dimensão têm vindo a registar adesão da população, sugerindo que o investimento neste tipo de estruturas, é uma resposta eficaz à necessidade da população desfrutar de EVU e espaços de convívio comunitário na proximidade das áreas residenciais. No entanto, em Coimbra os espaços continuam a concentrar-se junto ao rio.

Em Salamanca está em vigor o Plano Geral de 2007 (PGOU 2007), cujo objectivo é acabar com os déficits de EVU nalguns bairros da cidade, pelo que se propõe o incremento da estrutura verde através da integração das hortas urbanas e espaços florestais localizados na periferia. Estas actuações confirmam a trajectória que começou com o Plano Geral de 1984 (PGOU, 1984) e que impulsionou a criação de 18 EVU espalhados pela cidade.

\section{METODOLOGIA}

A realização deste estudo teve por base dois pressupostos de análise territorial para as cidades de Coimbra e Salamanca: i) Delimitação das cidades e dos centros 
históricos; ii) Definição de EVU. Para responder ao primeiro pressuposto utilizaram-se, para Coimbra, os limites estabelecidos para o centro histórico da cidade no Plano Director Municipal (PDM). Para Salamanca, a delimitação da cidade foi calculada com base nas parcelas com descontinuidades espaciais inferiores a $200 \mathrm{~m}$ de solo não urbano, segundo a metodologia de Nel-lo e Muñoz (2004), enquanto o limite do centro histórico de Salamanca corresponde às antigas muralhas da cidade, fixado no Plan General de Ordenación Urbana (PGOU).

Tendo em conta o facto de ambos os países aplicarem conceitos distintos na classificação do que é ou não um espaço verde urbano, optou-se por aplicar um critério comparável, que pode ir além do estabelecido na legislação. Nesse sentido, seleccionaram-se os EVU com um mínimo de 0,9 ha, nos quais é possível realizar actividades lúdicas ou desportivas; de acordo com a metodologia definida por Gómez (2012, 2013). A literatura (Canosa et al., 2003; Van Herzele e Wiedemann, 2003; Santana et al., 2007a) tem revelado que o espaço verde urbano com dimensão igual ou superior a 0,9 ha responde a algumas funções, nomeadamente lazer, desporto ou passeio, justificando a maior parte das visitas dos utilizadores desses espaços públicos.

Após a selecção dos EVU, analisou-se a respectiva génese e distribuição nas duas cidades. Foi também avaliada a acessibilidade da população, com recurso a ferramentas de Sistemas de Informação Geográfica, segundo dois processos: i) Determinação da área de influência de cada EVU público (buffering), utilizando uma distância de 400 metros, para dimensões entre 0,9 e 10 ha e de 800 metros, para EVU de dimensão superior (segundo metodologia de Van Herzele e Wiedemann, 2003); e ii) Identificação da distância (spatial join), em linha recta, entre o centróide de cada bairro ou subsecção estatística ${ }^{v}$ e o EVU mais próximo (segundo metodologia de Santana et al., 2008; 2010).

No presente estudo, a unidade geográfica de análise utilizada foi o Bairro, no caso de Salamanca, e a Subsecção Estatística em Coimbra, por representarem a desagregação territorial de menor dimensão utilizada nos respectivos Censos.

Para se analisar a utilização dos EVU pelos cidadãos foi aplicado um inquérito aos seus utilizadores, segundo a metodologia aplicada por Gómez (2012), baseada nos estudos de Chiesura (2004), isto é, aplicou-se um ratio de 2,56 inquéritos por hectare de espaço verde. Deste modo, obteve-se uma amostra de 540 utilizadores, dos quais 269 em Coimbra e 271 em Salamanca. Este inquérito, para além de focar as características individuais dos utilizadores (idade, género, escolaridade, profissão e local de residência), procurou definir um padrão de utilização (frequência de utilização, horário de visita, proximidade à residência, tempo e modo de deslocação) e avaliar as razões de procura dos EVU (motivo da utilização, sensações produzidas pelos espaços e tipos de constrangimentos à utilização). 


\section{AVALIAÇÃO DOS ESPAÇOS VERDES URBANOS EM COIMBRA E SALAMANCA}

\section{Génese dos espaços verdes nas duas cidades}

A distribuição dos EVU nas cidades em estudo é bastante distinta (fig. 2). Salamanca tem 26 EVU com uma distribuição pulverizada por toda a cidade, totalizando 100 ha. A cada salmantino correspondem $6,4 \mathrm{~m}^{2}$ de espaço público tratado. Em Coimbra contam-se 9 EVU públicos, com dimensão superior a 0,9 ha, na maioria concentrados próximo do centro histórico de Coimbra, totalizando $105,1 \mathrm{ha}^{\mathrm{vi}} \mathrm{e}$ um ratio de $10,7 \mathrm{~m}^{2}$ por habitante.

Apesar das diferenças identificadas quanto à sua distribuição nas duas cidades, são visíveis três etapas na génese dos EVU públicos, referenciadas por Sanesi e Chiarello (2006), que são, aliás, comuns à maioria dos países mediterrâneos (fig. 3): 1) na cidade histórica ou medieval, com ruas estreitas e irregulares e pequenos becos e ruelas, onde praticamente não existe qualquer EVU excepto alguns jardins históricos de dimensão muito reduzida; 2) na cidade construída nos séculos XVIII e XIX, onde os EVU dominam ao longo de avenidas e em algumas praças (que testemunham a sua génese: ordens religiosas e universidade); e 3) na área urbana construída no final do século XX, com espaços residenciais bem definidos e onde se têm construído novos EVU, de acordo com as exigências da legislação e respondendo à estratégia delineada pelos municípios.

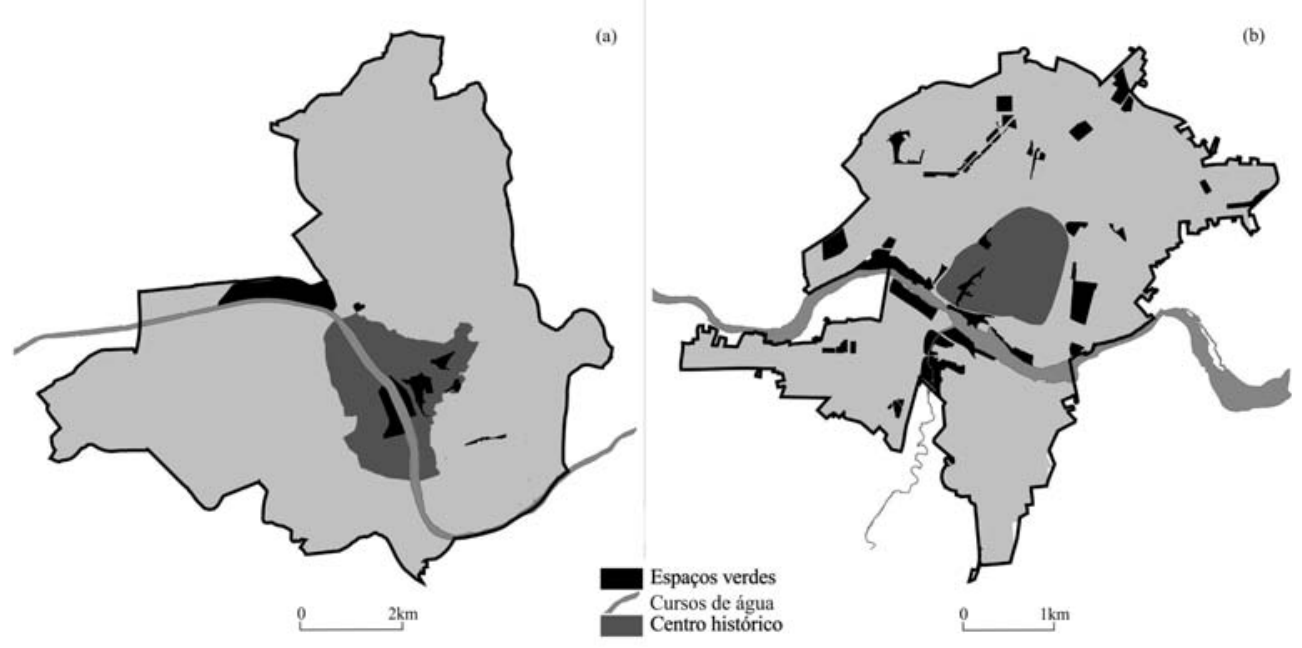

Fig. 2 - Espaços verdes urbanos nas cidades de Coimbra (a) e Salamanca (b).

Fig. 2 - Urban green spaces in the cities of Coimbra (a) and Salamanca (b).

Fonte: Elaborado a partir de cartografia do Instituto Tecnológico Agrario de Castilla y León (Salamanca) e do Gabinete de Informação Geográfica da Câmara Municipal de Coimbra (2007) 


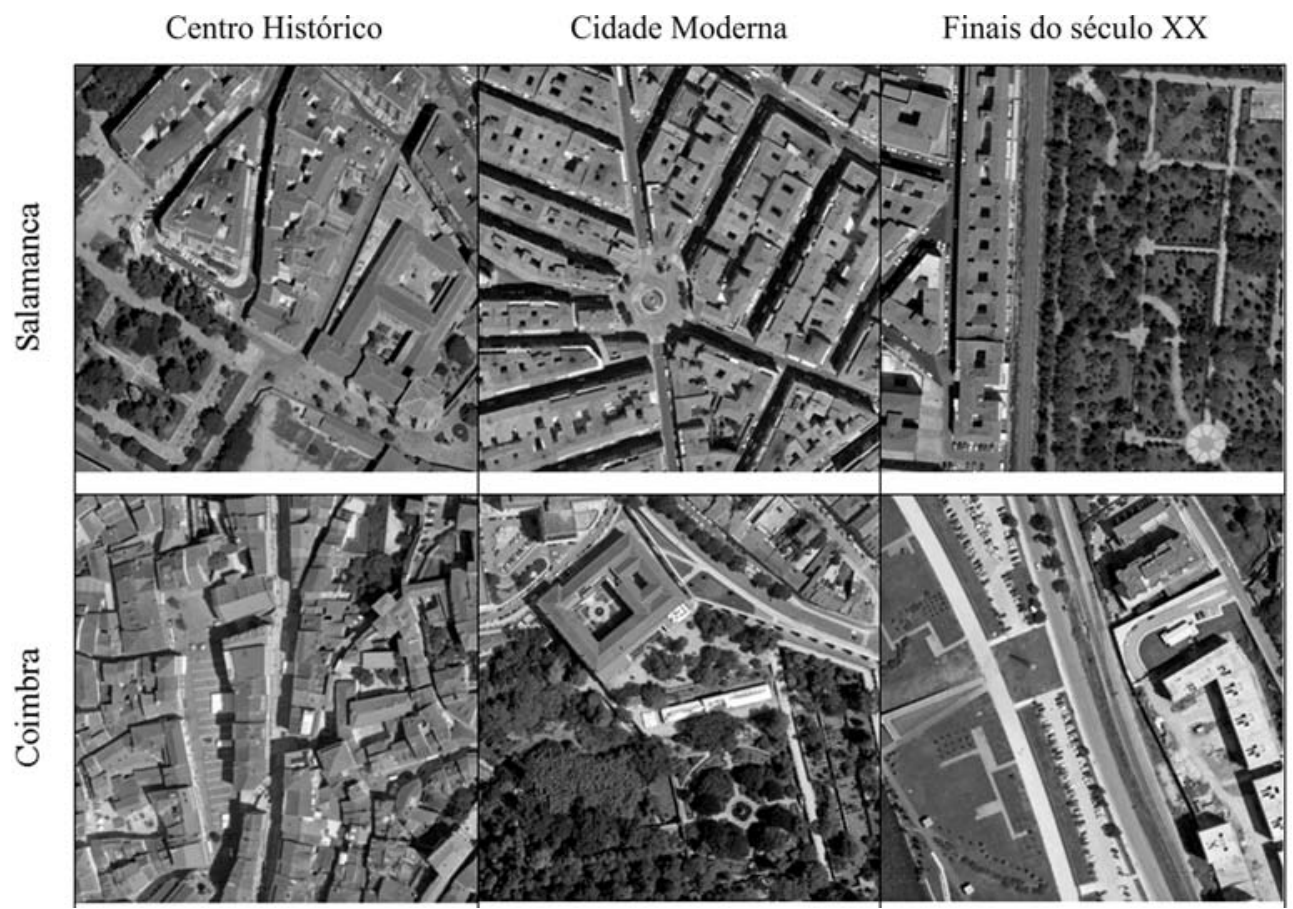

Fig. 3 - Evolução da tipologia de espaços verdes urbanos segundo Sanesi e Chiarello (2006).

Fig. 3 - Types of urban green spaces according to Sanesi and Chiarello (2006).

Fonte: Elaborado a partir de Google Earth (imagens de satélite de 2006 - Coimbra - e de 2008 - Salamanca).

Este tipo de evolução dos EVU observa-se nas duas cidades:18 dos 26 de Salamanca e 4 dos 9 EVU de Coimbra surgiram nos últimos 30 anos. Os EVU construídos antes deste período têm a sua génese associada às Universidades e às Ordens Religiosas. Em Coimbra, a Universidade foi a responsável pela criação, no século XVIII, do Jardim Botânico que, durante muito tempo, foi a maior estrutura verde pública na cidade. A Universidade foi, também, a impulsionadora de um parque verde com mais de 9 ha em Salamanca, construído no final do século XX (espaço verde urbano da Faculdade de Comunicação). As ordens religiosas tiveram, igualmente, papel preponderante na construção destes espaços públicos: em Salamanca, quatro EVU (Campo de São Francisco, Parque dos Jesuítas, Parque Picasso e Parque Verde Urbano das Salesas) e em Coimbra apenas um (Parque de Santa Cruz, também conhecido por Jardim da Sereia).

\section{Distribuição e acessibilidade}

Apesar da clara distinção na génese dos EVU, as diferenças entre as duas cidades são bem visíveis: em Coimbra, a maioria concentra-se próximo da cidade histórica; em Salamanca, há dispersão pelo território da cidade, sendo preferencialmente, na periferia do centro histórico ou junto dos novos espaços de crescimento urbano (fig. 4). 


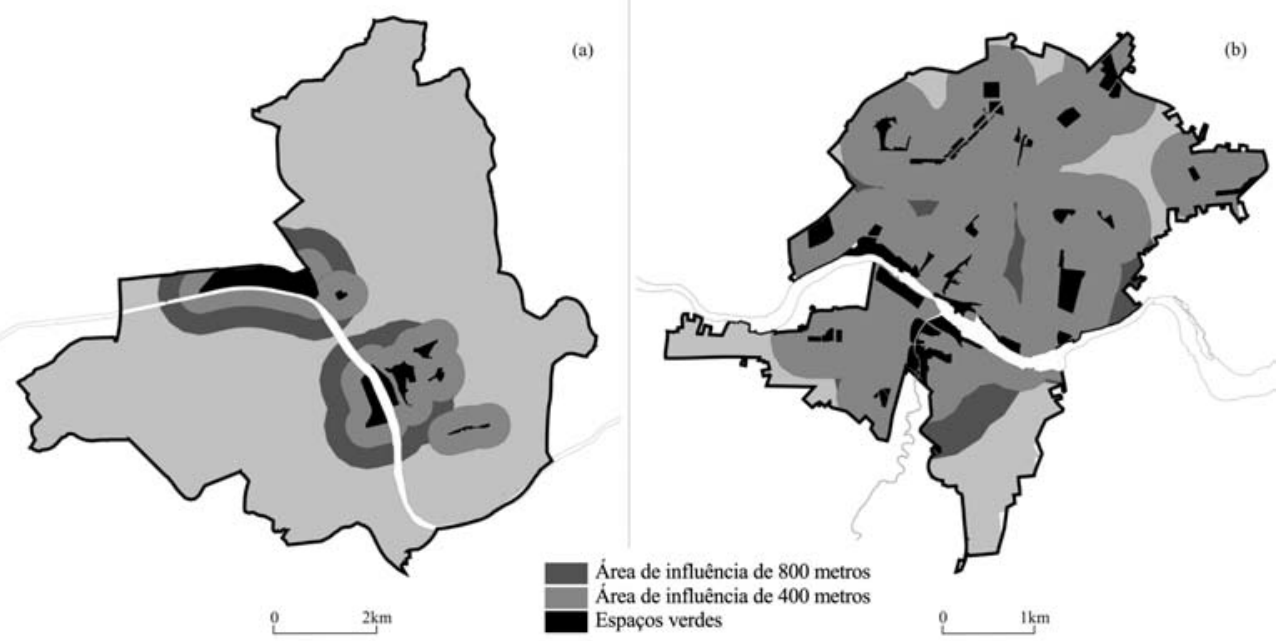

Fig. 4 - Acessibilidade aos espaços verdes urbanos em Coimbra (a) e Salamanca (b).

Fig. 4 - Accessibility to urban green spaces in Coimbra (a) and Salamanca (b).

Fonte: Elaborado a partir de cartografia do Instituto Tecnológico Agrario de Castilla y León (Salamanca) e do Gabinete de Informação Geográfica da Câmara Municipal de Coimbra (2007)

O carácter extensivo do crescimento da cidade de Coimbra tem fragilizado, ao longo dos últimos anos, a relação de proximidade entre a população e os EVU, por estes não acompanharem a distribuição da população pelo território. Se se considerar que a acessibilidade decresce com a diminuição da mobilidade em modos de deslocação suaves (entre a origem e o destino), a distribuição dos EVU pelo território próximo dos potenciais utilizadores - é condição essencial para uma efectiva utilização destes espaços públicos. O inverso também é verdadeiro, facto visível na cidade de Coimbra.

Analisando a distribuição da população e dos EVU nas duas cidades, verificam-se níveis de acessibilidade muito diferentes: em Salamanca 82,6\% da superfície urbana encontra-se na área de influência de um deles ${ }^{\text {vii, }}$, estimando-se que 23991 residentes tenham acessibilidade geográfica prejudicada por viverem fora dos limiares identificados anteriormente. Em Coimbra apenas $21,7 \%$ da área da cidade tem boa acessibilidade aos EVU, tendo sido contabilizadas 62341 residentes com má acessibilidade aos EVU (fig. 4). Este facto é o resultado da localização, concentrada, dos EVU públicos próximo do centro da cidade (seis dos nove), coincidindo com a área de menor densidade populacional, ficando assim uma grande área residencial muito afastada desses espaços. Em 4433 hectares da cidade, há 59192 residentes que ficam a mais de mil metros dos EVU e 28130 residentes a mais de dois mil metros (fig. 5). Pelo contrário, em Salamanca, eles estão distribuídos por toda a cidade, constituindo-se como uma rede que confere aos residentes níveis de acessibilidade e frequências de utilização elevadas (fig. 4). Por isso, há apenas 1043 residentes a uma distância superior a 2500 metros dos EVU, correspondendo a uma área de 73,4 ha (fig. 5). 


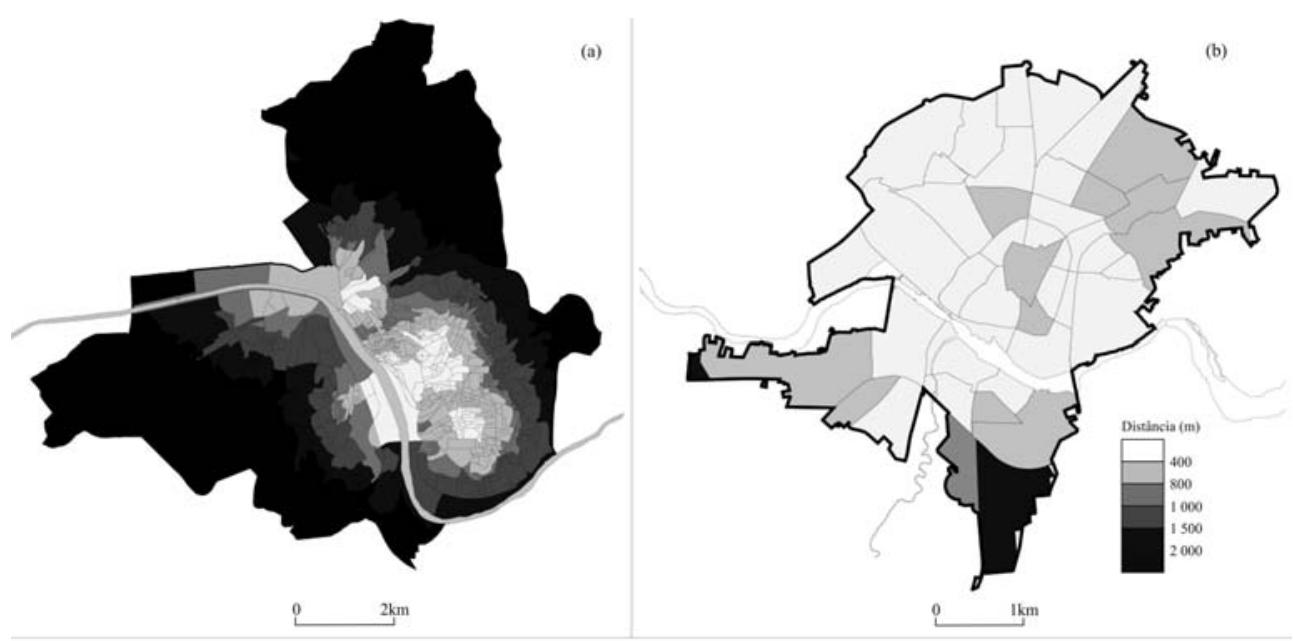

Fig. 5 - Distância do centróide da subsecção ou do bairro ao espaço verde mais próximo em Coimbra (a) e Salamanca (b).

Fig. 5 -Distance from the centroid of the subsection or neighbourhood to the nearest green space in Coimbra (a) and Salamanca (b).

Fonte: Elaborado a partir de cartografia do Instituto Tecnológico Agrario de Castilla y León (Salamanca), do Gabinete de Informação Geográfica da Câmara Municipal de Coimbra (2007) e dados estatísticos do INE-ES e INE-PT (2011)

\section{Perfil dos utilizadores}

Os salmantinos utilizam mais os EVU do que os conimbricenses, pois $62 \%$ deles frequenta-os em média, mais de 5 vezes por semana, enquanto em Coimbra eles não chegam a $15 \%$ dos inquiridos, tendo a maioria deles afirmado que os frequenta apenas uma ou duas vezes por semana (fig. 6).

O perfil dos utilizadores dos EVU em Coimbra e Salamanca é também distinto. Em Coimbra, quase metade são jovens, com idades compreendidas entre os 18 e os 30 anos $(45,3 \%)$ representando a população sénior pouco mais de 5\%. Em Salamanca, os jovens são também o grupo mais representativo $(32,1 \%)$ mas a população sénior tem maior expressão do que em Coimbra (20,3\%), principalmente do sexo masculino, com $15,3 \%$ dos inquiridos (fig. 7 ).

A distribuição por género é semelhante nas duas cidades, embora o número de homens inquiridos seja maior (fig. 7). Também em termos do horário de utilização se verificam semelhanças (fig. 8). O período que concentra mais utilizadores é a tarde: $57,3 \%$ dos conimbricenses e 53,2\% dos salmantinos visitam os EVU entre as 16 e as 20 horas. No entanto, se em Salamanca mais de um terço dos inquiridos referiu utilizá-los de manhã, com principal destaque para a população sénior, em Coimbra são poucos os seus frequentadores neste horário, pois $21 \%$ dos inquiridos prefere o período entre as 14 e as 16 horas, quando decorre o descanso pós almoço em Espanha, estando EVU salmantinos praticamente vazios (só 4,2\% dos inquiridos). 


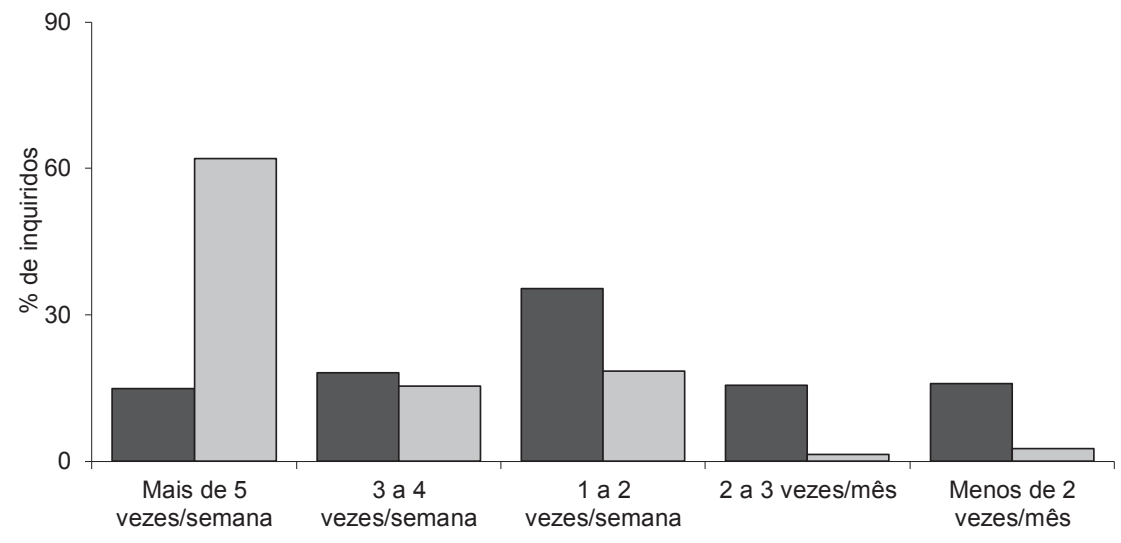

Frequência

$\square$ Coimbra $\square$ Salamanca

Fig. 6 - Frequência de utilização dos espaços verdes urbanos de Coimbra e Salamanca.

Fig. 6-Frequency of use of urban green spaces in Coimbra and Salamanca.

Fonte: Inquéritos realizados pelos autores em 2012
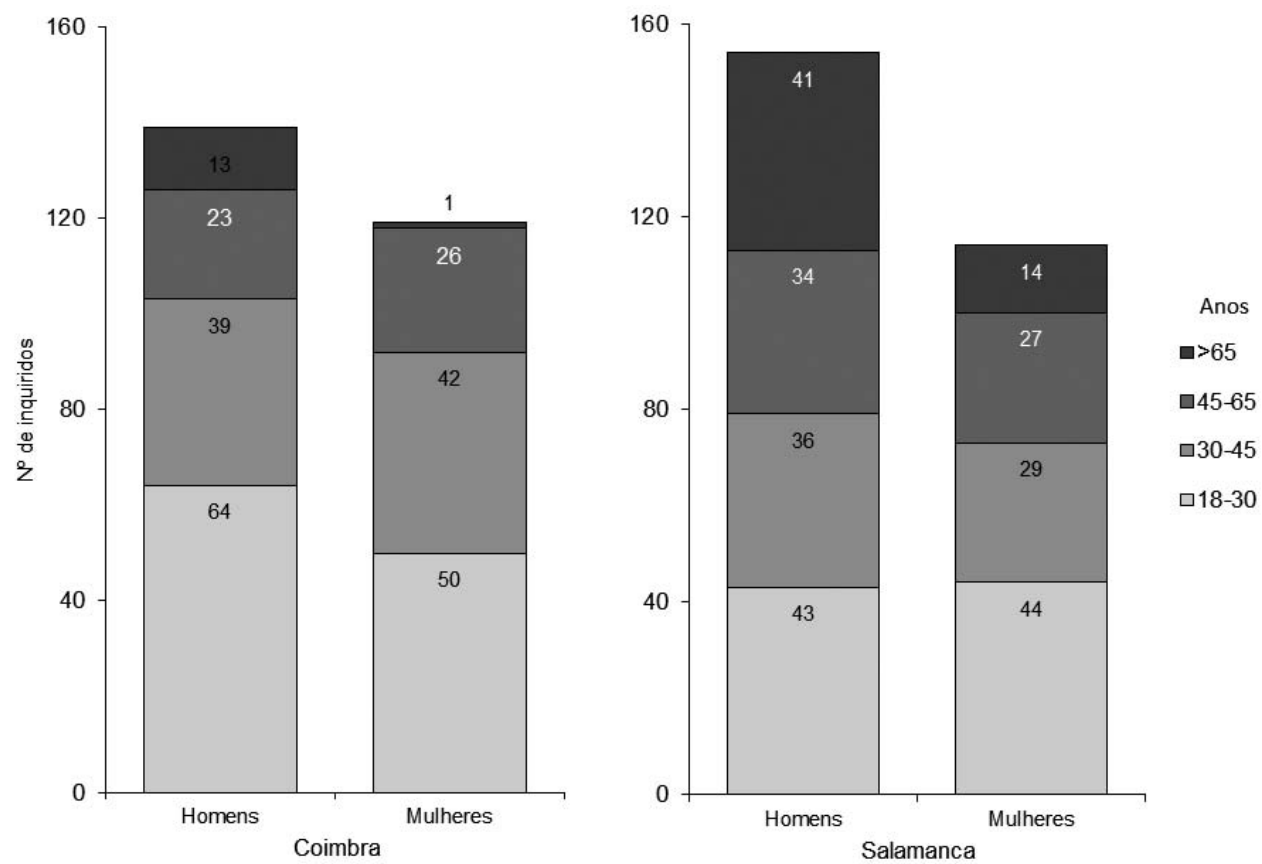

Fig. 7 - Caracterização dos utilizadores de espaços verdes urbanos de Coimbra e Salamanca.

Fig. 7 - Characterization of users of urban green spaces in Coimbra and Salamanca.

Fonte: Inquéritos realizados pelos autores em 2012 


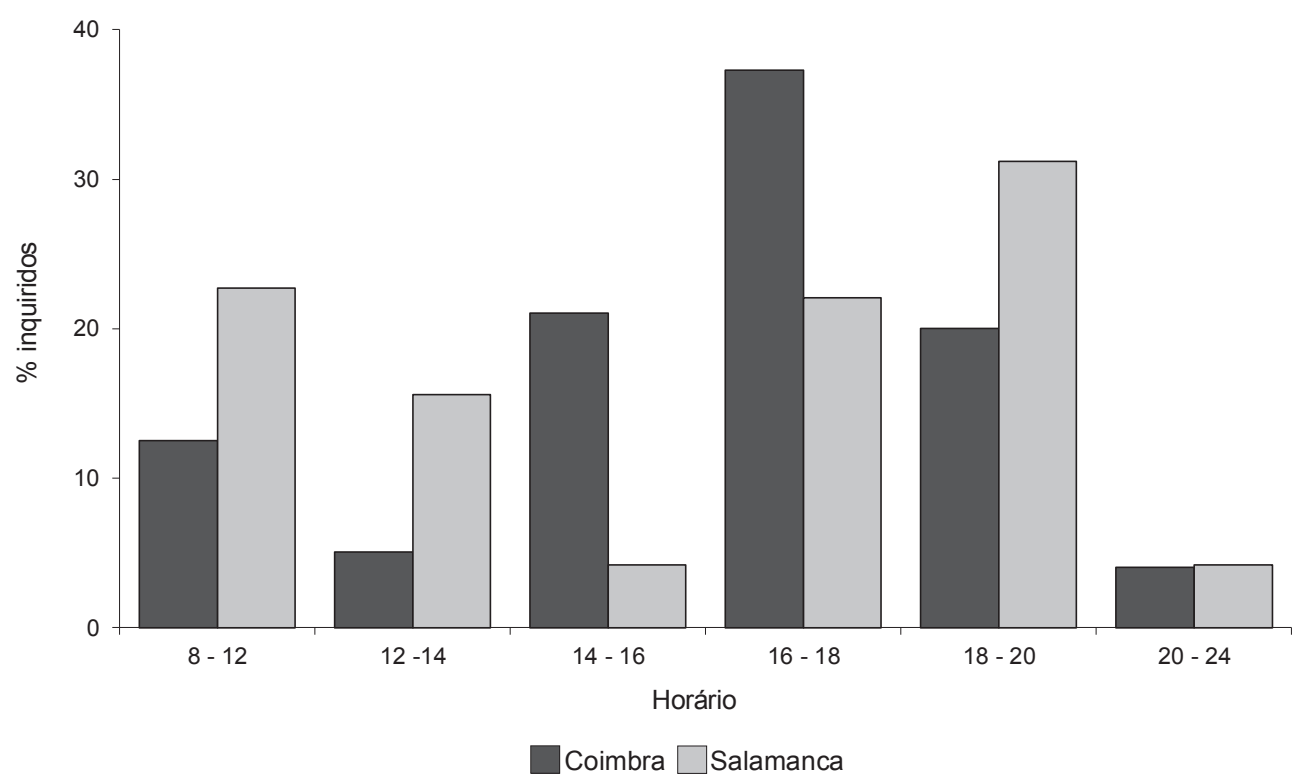

Fig. 8 - Horários de visitas dos espaços verdes urbanos.

Fig. 8 -Most popular time for visiting urban green spaces.

Fonte: Inquéritos realizados pelos autores em 2012

\section{Tempo de deslocação e motivo de utilização}

São várias as motivações que levam a população a deslocar-se a um espaço verde - prática de desporto, relaxamento, passeio, etc. - mas as motivações são distintas em Coimbra e em Salamanca (fig. 9). A distância a percorrer entre a residência e o parque é importante em Salamanca: três em cada quatro inquiridos referiram ser a proximidade à residência o motivo de escolha dos EVU, ao passo que em Coimbra esta percentagem é muito menor (16,7\%). De facto, quando se questionou a duração da deslocação entre a residência e o EVU mais próximo, apenas $18 \%$ dos inquiridos referiu morar a menos de 5 minutos, enquanto em Salamanca esse valor sobe para $54,5 \%$ (fig. 10). Em Coimbra, mais de metade dos inquiridos referiu demorar entre 5 a 15 minutos $(55,6 \%)$ deslocando-se de carro $(57,2 \%)$, o que é inevitável dada a distância a vencer. Apenas $30 \%$ dos inquiridos em Coimbra referiu ter lá chegado a pé, tendo $3,3 \%$ utilizado transporte público (2,6\% - autocarro; $0,7 \%$ - comboio). Estes valores traduzem a dificuldade sentida pelos conimbricenses para aceder aos EVU, uma vez que, como se referiu, quase $80 \%$ da cidade tem acessibilidade reduzida a estes espaços. 


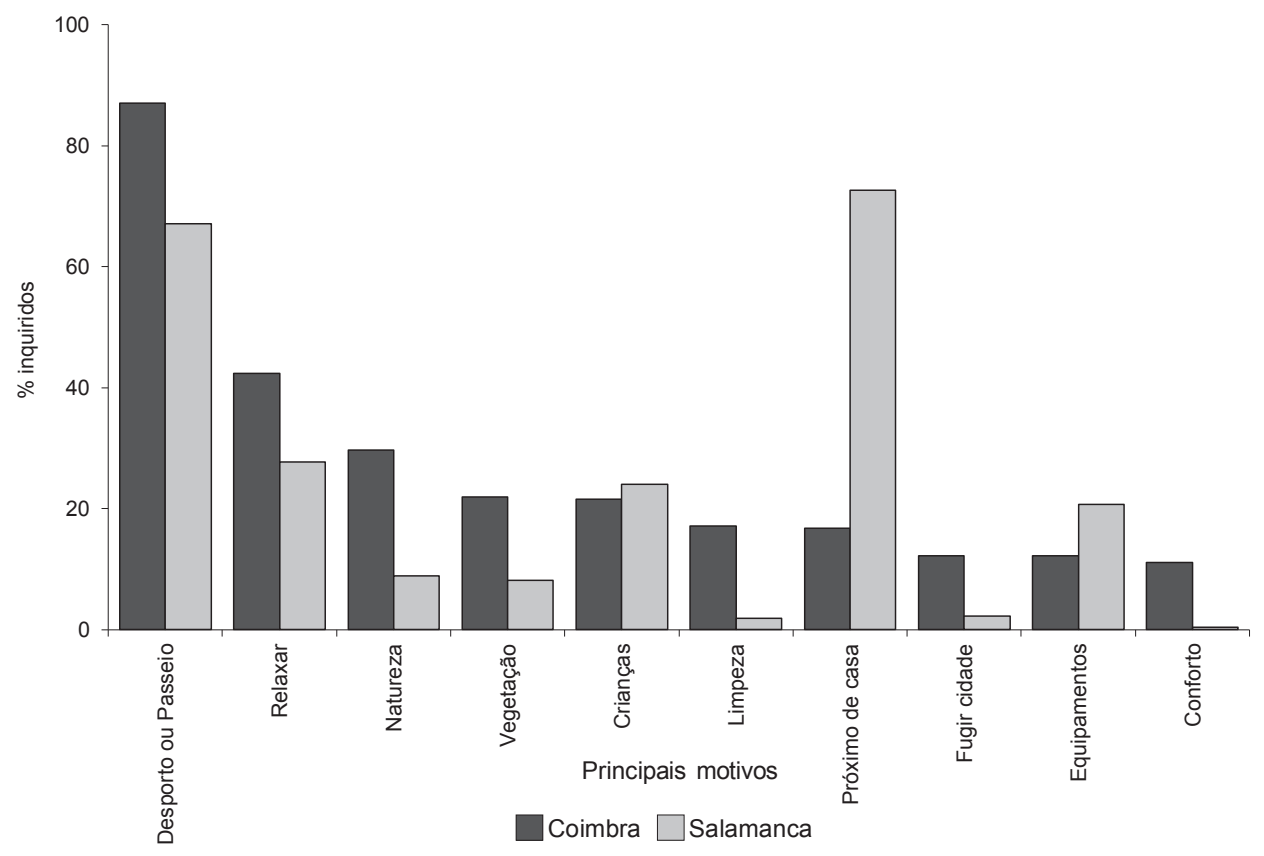

Fig. 9 - Motivação na frequência dos espaços verdes urbanos de Coimbra e Salamanca.

Fig. 9 - Reason for visiting urban green spaces in Coimbra and Salamanca.

Fonte: Inquéritos realizados pelos autores em 2012

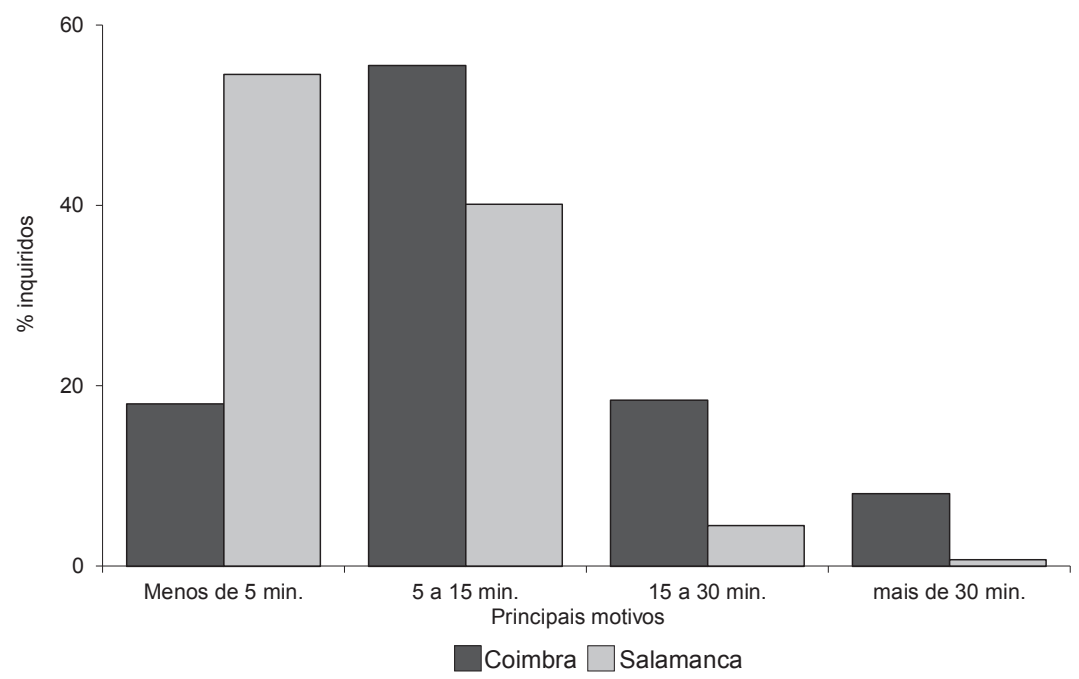

Fig. 10 - Tempo de deslocação entre a residência e o espaço verde urbano, em Coimbra e em Salamanca.

Fig. 10 - Travel time between residence and urban green space in Coimbra and Salamanca.

Fonte: Inquéritos realizados pelos autores em 2012 
A escolha do EVU, em Coimbra, faz-se em função das actividades a realizar e não pela proximidade à residência, contrariamente ao observado em Salamanca. Em Coimbra pratica-se desporto ou passeia-se (87\%). Embora com valores mais baixos, estas actividades também foram assinaladas por uma grande quantidade de salmantinos (67,2\%). Em Coimbra segue-se o "relaxamento" (42,4\%), o "contacto com a natureza" (29,7\%) e o "sentimento de escapar da cidade" (12,3\%). Em Salamanca, o "relaxamento" foi, também, uma justificação muito importante para as visitas. Contudo, o "contacto com a natureza" e o "sentimento de escapar da cidade" são menos expressivos do que em Coimbra. A possibilidade de passear com as crianças motivou um em cada quatro inquiridos, em ambas as cidades.

As características dos EVU também influenciam a decisão da visita e a escolha do espaço a visitar. O tipo de vegetação existente, o grau de limpeza, os equipamentos que oferece e a dimensão motivaram $60,3 \%$ dos inquiridos em Coimbra e 43,5\% em Salamanca.

As sensações reportadas pelos visitantes dos EVU, no dia da entrevista, são semelhantes nas duas cidades: dois em cada três inquiridos afirmaram que quando os visitam "sentem-se bem em contacto com a natureza"; tendo o sentimento de liberdade sido reconhecido por 45,4\%, em Coimbra e 36,9\%, em Salamanca (fig. 11).

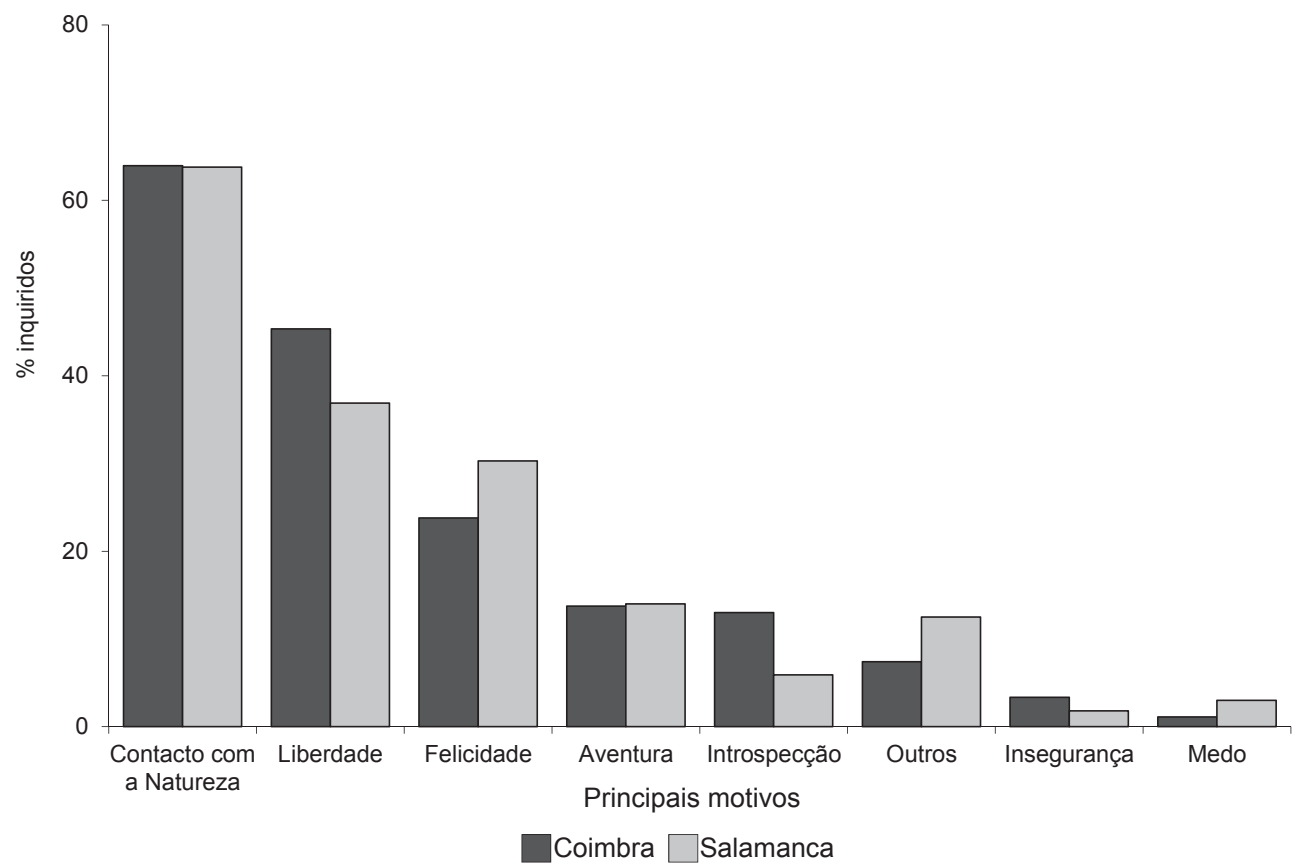

Fig. 11 - "Sensações" produzidas pelos espaços verdes urbanos de Coimbra e Salamanca.

Fig. 11 - "Feelings" of the urban green spaces visitors in Coimbra and Salamanca.

Fonte: Inquéritos realizados pelos autores em 2012 
Verificou-se ainda que a sensação de felicidade durante a permanência no EVU, é superior em Salamanca (um em cada três inquiridos), seguido, em ambas as cidades, pelo "sentimento da aventura" e do "(re)encontro consigo próprio". Estas respostas permitem concluir que eles são percepcionados como lugares onde as pessoas se sentem bem e se "pode escapar/fugir do stress urbano". Todavia, para mais de $4 \%$ dos inquiridos é, também, paradoxalmente, um lugar de insegurança e de medo, o que pode desmotivar futuras deslocações a EVU.

\section{Sugestões para alteração das características dos espaços verdes}

Em Salamanca, 64,2\% dos inquiridos referiram a necessidade de maior rigor na manutenção e limpeza dos EVU, desejo manifestado em Coimbra por $42 \%$ dos frequentadores (fig. 12). Verificou-se que em Salamanca, o mobiliário urbano, os equipamentos e a vegetação estão deteriorados. Este facto poderá estar associado, por um lado, à deficiente gestão destes espaços por parte das autoridades locais e, por outro, aos comportamentos destruidores ou mesmo violentos de alguns utilizadores. Cerca de $8 \%$ dos inquiridos referiu a urgência da intensificação da vigilância, de forma a reduzir o vandalismo. Verificou-se, ainda, que a presença de cães, na maioria sem trela, se traduz em inquietação ou insegurança $(12,2 \%)$.

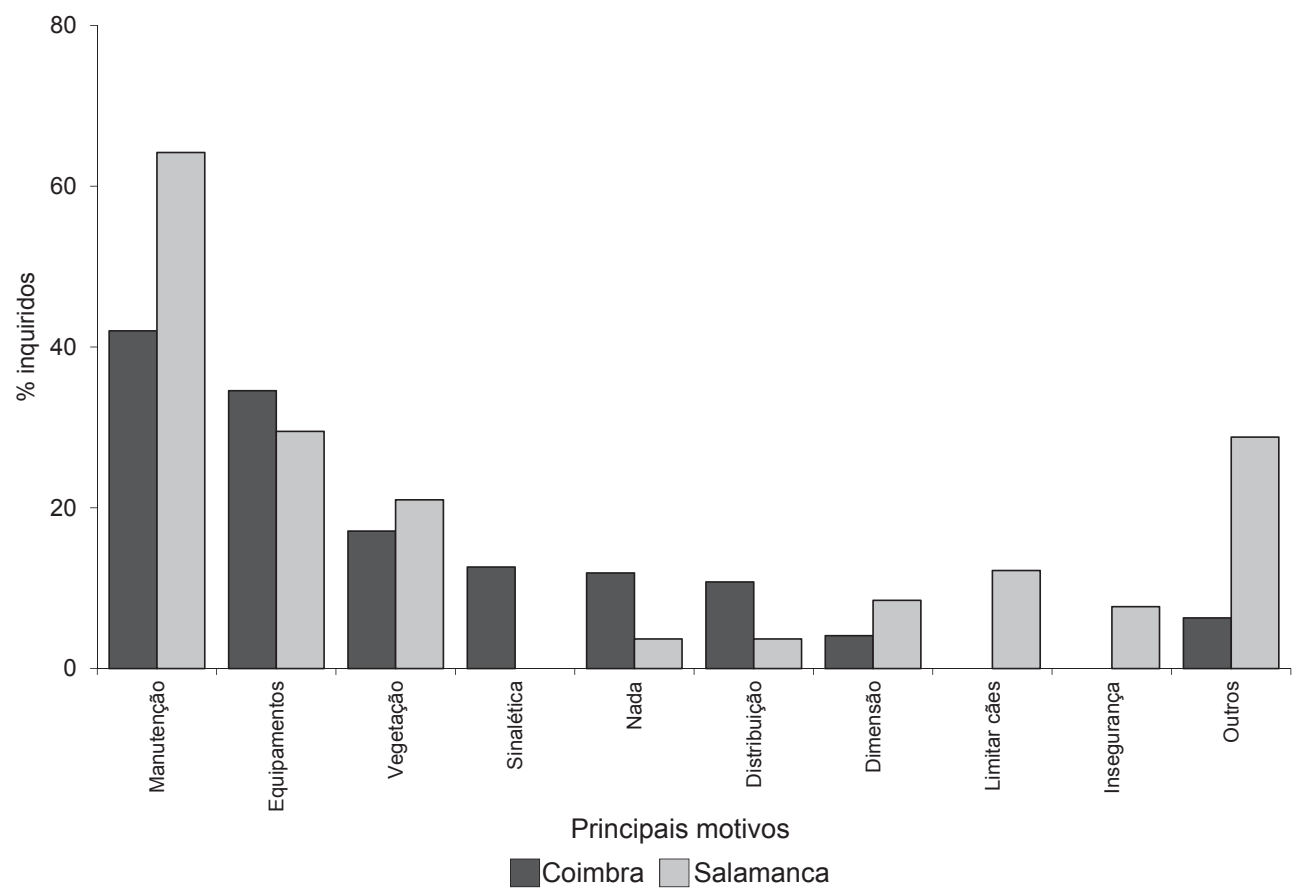

Fig. 12 - Alterações nos espaços verdes urbanos sugeridas pelos inquiridos em Coimbra e Salamanca.

Fig. 12 - Alterations to urban green spaces of Coimbra and Salamanca suggested by respondents. 
Em Coimbra, para além da manutenção e limpeza dos EVU, foi referida a necessidade de aumentar a quantidade e qualidade dos equipamentos $(34,6 \%)$, da vegetação $(17,1 \%)$ e da sinalética $(12,6 \%)$. Apesar das diferenças entre as duas cidades, na apreciação das características dos EVU, existe uma percentagem apreciável de cidadãos que considera não ser necessário alterar ou melhorar esses espaços, principalmente em Coimbra.

\section{DISCUSSÃO DOS RESULTADOS E CONCLUSÕES}

Este trabalho permitiu aprofundar o conhecimento dos EVU das duas cidades da Península Ibérica, podendo vir a ser útil no seu planeamento, pois foi a primeira vez que se desenvolveu um estudo com estas características nas cidades de Salamanca e Coimbra.

A maior parte dos EVU de Coimbra tem mais de cem anos tendo nas últimas décadas sido construídos apenas quatro de dimensão adequada para serem incluídos nesta investigação, localizados maioritariamente nas margens do Rio Mondego. De facto, a política local dos últimos vinte anos pautou-se pela concentração de grandes áreas de espaço verde junto ao rio, aproveitando as suas margens. Em Salamanca foram construídos dezoito EVU nas últimas três décadas, acompanhando o crescimento da cidade para novos bairros e incrementando de maneira destacada as infra-estruturas verdes mostrando uma trajectória positiva impulsionada pelo planeamento urbano regional que, mesmo assim, não foi capaz de solucionar os déficits herdados de etapas anteriores.

De facto, a aposta do Município de Coimbra tem sido recentrar a cidade no Rio, dando primazia à concentração dos EVU nesta área e não necessariamente à proximidade da população, o que tem consequências nos níveis de utilização. A opção de Salamanca foi semelhante, valorizando as zonas ribeirinhas dos rios e riachos, para expansão presente e futura da infra-estrutura verde, mas estas actuações foram acompanhadas por uma sistemática criação de EVU públicos em novos bairros, segundo as normas do urbanismo regional.

Coimbra apresenta um ratio de EVU por habitante superior ao de Salamanca embora apenas satisfaça as necessidades de proximidade a cerca de 30.000 residentes, contrariamente ao que se observa em Salamanca (cerca de 130.000 habitantes têm boa ou muito boa acessibilidade). A dispersão da população, por um lado, e a concentração dos EVU, por outro, justifica a acessibilidade e a utilização que observamos em Coimbra, muito diferente de Salamanca. A proximidade da residência ou do local de trabalho é uma das principais razões de utilização dos EVU em Salamanca, o que não acontece em Coimbra. Por outro lado, nenhuma das cidades atinge o valor global desejável para a estrutura verde urbana $-40 \mathrm{~m}^{2} /$ habitante - defendido por diversos autores (Magalhães, 1992; Tzoulas et al., 2007; Santana et al., 2007), nem o valor adoptado por diversos países desenvolvidos (Wang, 2009) - $20 \mathrm{~m}^{2} / \mathrm{habi}$ tante. Apenas Coimbra ultrapassa ligeiramente o rácio definido pela Organização 
Mundial de Saúde e a Organização das Nações Unidas para Agricultura e Alimentação (Kuchelmeister, 1998) - 9 m²/habitante.

A distribuição dos EVU condiciona a acessibilidade geográfica dos residentes nas cidades analisadas, o que foi confirmado pelas respostas dos cidadãos sobre o tempo que demoravam a chegar ao EVU mais próximo da residência. Em Coimbra, as longas distâncias entre a residência e os EVU obrigam à utilização de carro, condicionando a utilização e a frequência de utilização desses espaços públicos. Em Salamanca a utilização do carro nessa deslocação é muito menor e há maior frequência de utilização dos EVU. No entanto, as sensações dos inquiridos relativamente ao seu uso são semelhantes em ambas as cidades, predominando "o contacto com a natureza" e o "sentimento de liberdade".

Comparando os resultados obtidos nos inquéritos em Coimbra e Salamanca com o trabalho que Chiesura (2004) realizou num parque da cidade de Amsterdão (Holanda) viii, verifica-se que as populações inquiridas apresentam hábitos distintos. Para os utilizadores do Vondelpark, em Amesterdão, as características do espaço não são o principal motivo, mas sim a possibilidade de "descomprimir do ritmo de vida", procurando o "relaxamento", "escapando ao ritmo acelerado da cidade" e recuperando o "contacto com a natureza". A percentagem destes motivos é dupla quando comparado com a de Coimbra e tripla relativamente ao verificado em Salamanca. Por outro lado, em Amsterdão os EVU são menos utilizados para a prática de desporto ou passeio, pois eles são sobretudo frequentados para se apreciar a vegetação e a natureza. Não obstante, os frequentadores de EVU das três cidades têm sentimentos semelhantes quando se referem ao contacto com a natureza.

Embora os problemas sentidos em Coimbra e Salamanca sejam diferentes foram identificados aspectos a necessitar de melhorias, com destaque para a necessidade de reforçar, nas duas cidades, a manutenção e a limpeza e, adicionalmente em Salamanca, a segurança.

No que diz respeito à acessibilidade geográfica, será necessário (re) desenhar uma rede de EVU distribuída pela cidade, principalmente no caso de Coimbra. De facto, verificou-se que, nesta cidade, com densidade populacional seis vezes inferior à da Salamanca, a população fica mais distante geograficamente do EVU.

Em síntese, é tão importante conhecer a oferta de EVU ( $\mathrm{m}^{2} /$ habitante) como a sua distribuição pelo território, pois ambas determinam a utilização e a frequência de utilização de EVU. O exemplo de Coimbra mostrou, por um lado, que o indicador tradicional de EVU por habitante é insuficiente, por ignorar as barreiras e constrangimentos ao seu acesso e utilização, bem como a distância a vencer entre o local de residência ou de trabalho e o EVU, o que mostra a necessidade de rever o seu planeamento. A presença de verde na cidade, com distribuição, dimensão (superior a 0,9 ha) e enquadramento suficiente para a prática diária de actividades lúdicas ou desportivas, deve ser entendida como um dos elementos da morfologia urbana estreitamente ligada à distribuição da população no território. São por isso necessárias intervenções que potenciem as funções do EVU no tecido urbano e o reconhecimento e valorização das múltiplas tipologias de verde neles presentes. 


\section{AGRADECIMENTOS}

Agradecimento a Ângela Freitas, Luís Monteiro, Magda Palhinha e Marina Miranda, que apoiaram os autores na realização dos inquéritos em Coimbra e Salamanca, e aos revisores anónimos, cujo valioso contributo permitiu aperfeiçoar a qualidade científica do presente artigo.

Este trabalho foi realizado com o apoio dos projectos "SMAILE - Saúde Mental - Avaliação do Impacte das condicionantes Locais e Económicas" (PTDC/ATP-GEO/4101/2012) e "Planeamento Urbano Saudável. Desenvolvimento e aplicação de um modelo ao caso da Amadora" (POCTI/GEO/ 45730/2002), ambos financiados pela Fundação para a Ciência e Tecnologia.

\section{BIBLIOGRAFIA}

Alcoforado M, Andrade H (2007) Clima e saúde na cidade. Implicações para o ordenamento. In Santana P (ed.) A Cidade e a Saúde. Almedina, Coimbra: 99-118.

Canosa E, Sáez E, Sanabria C, Zavalla I (2003) Metodología para el estudio de los parques urbanos: la Comunidad de Madrid. Geofocus - Revista Internacional de Ciencia y Tecnología de la Información Geográfica, 3: 160-185.

Chiesura A (2004) The role of urban parks for the sustainable city. Landscape and Urban Planning, 68: 129-138.

Coombes E, Jones A, Hillsdon M (2010) The relationship of physical activity and overweight to objectively measured green space accessibility and use. Social Science and Medicine, 70(6): 816-822.

De Vries S, Verheij R A, Groenewegen P P, Spreeuwenberg P (2003) Natural environments - healthy environments? An exploratory analysis of the relationship between greenspace and health. Environment and Planning, A35(10): 1717-1731.

Doyle S, Kelly-Schawartz A, Scholossberg M, Stockard J (2006) Active community environments and health: the relationship of walkable and safe communities to individual health. Journal of the American Planning Association, I: 19-31.

Fonseca F, Gonçalves A, Rodrigues O (2010) Comportamentos e percepções sobre os espaços verdes na cidade de Bragança. Finisterra - Revista Portuguesa de Geografia, 15(89): 119-139.

Foster C, Hieldson M, Jones A, Panter J (2007) Assessing the relationship between the quality of urban green space and physical activity. CABE Space Report, Londres: Cabe Space.
Ganho N (1996) Espaços verdes no interior do tecido urbano: contrastes topoclimáticos, influência bioclimática e riscos de poluição - o caso de Coimbra. Territorium, 3: 35-56.

Gómez A (2013) Localización y acceso al verde urbano de la ciudad de Salamanca. Boletín de la $A G E, 63: 125-145$.

Gómez A (2012) La utilización de los espacios verdes. Estudio de caso en tres ciudades españolas. Cadernos de Geografia, 30/31: 193-202.

Hillsdon M, Panter J, Foster C, Jones A (2006) The relationship between access and quality of urban green space with population physical activity. Public Health, 120(12): 1127-1132.

Humpel N, Owen N, Leslie E, Marshall A, Bauman A E, Sallies J F (2004) Associations of location and perceived environmental attributes with walking in neighbourhoods. American Journal of Health Promotion, 18: 239-242.

Kim J, Kaplan R (2004) Physical and psychological factors in sense of community: New urbanist Kentlands and nearby Orchard Village. Environment and Behavior, 36(3): 313-340.

Knes I, Thorsson S (2006) Influences of culture and environmental attitude on thermal, emotional and perceptual evaluations of a public square. International Journal of Biometeorology, 50: 258-268.

Kuchelmeister G (1998) Urban forestry: present situation and prospects in the Asia and Pacific region. FAO Asia-Pacific Forestry Sector Outlook Study. Food and Agriculture Organization of the United Nations, Rome.

Kuo F, Sullivan W (2001) Aggression and violence in the inner city. Environment and Behavior, 33(4): 543-571. 
Leal C, Ganho N, Cordeiro A (2008) A influência dos espaços verdes da cidade de Coimbra (Portugal) no topoclima, no microclima e no conforto bioclimático. Cadernos de Geografia, 26/27: 333-341.

Madureira H, Andresen T, Monteiro A (2011) Green structure and planning evolution in Porto. Urban Forestry \& Urban Greening, 10(2): 141-149.

Magalhães M (1992) Espaços verdes urbanos. Lisboa. Direcção Geral do Ordenamento do Território.

Maas J, Verheij R, Groenewegwn P, De Vries S, Spreeuwenberg P (2006) Green space, urbanity, and health: how strong is the relation? Journal of Epidemiology \& Community Health, 60-7: 587-592.

Nel-lo O, Muñoz F (2004) El proceso de urbanización. In Romero J (ed.) Geografia humana: procesos, riesgos e incertidumbres en un mundo globalizado. Ariel, Barcelona: 255-332.

Nielsen T, Hansen K (2007) Do green areas affect health? Results from a Danish survey on the use of green areas and health indicators. Health \& Place, 13(4): 839-850.

Nilsson K, Randrup T, Tvedt T (1997) Aspectos tecnológicos del enverdecimiento urbano. In Krishnamurthy L, Nacimento J (eds.) Áreas verdes urbanas en Latinoamérica y el Caribe. Banco Interamericano de Desarrollo, México: 39-81.

Pêgo A, Simões J, Almeida A (2010) A rede ecológica da cidade de Coimbra - contributo para uma paisagem urbana sustentável. Livro de Actas do VI Seminário Latino-Americano de Geografia Física e II Seminário Ibero-Americano de Geografia Física. Coimbra. http://www.uc.pt/fluc/cegot/VISLAGF/actas/ tema3/antonio_pego

Pikorta T, Giles-Corti B, Bull F, Jamrozik K, Donovan A (2003) Developing a framework for assessment of the environmental determinants of walking and cycling. Social Science and Medicine, 56: 1693-1703.

Rochette A (2004) Uma nova perspectiva de ordenamento do território para o concelho de Coimbra. Uma abordagem segundo a "filosofia" dos Corredores Verdes". Cadernos de Geografia, 21/23: 67-78.

Sanesi G, Chiarello F (2006) Residents and urban green spaces: the case of Bari. Urban Forestry Urban Greenning, 4(3-4): 125-134.
Santana P, Costa C, Santos R, Loureiro A (2010) O papel dos espaços verdes urbanos no bem-estar e saúde das populações. Revista de Estudos Demográficos, 48: 6-33.

Santana P, Costa C, Santos R, Loureiro A (2008) Amadora, cidade saudável e activa. Universidade de Coimbra (policopiado).

Santana P, Nogueira H, Santos R, Costa C (2007a) Avaliação da qualidade ambiental dos espaços verdes urbanos no bem-estar e na saúde. In Santana P (ed.) A Cidade e a saúde. Almedina, Coimbra: 219-237.

Santana P, Nogueira H, Santos R, Costa C (2007b) Melhorar a saúde na Amadora intervindo no ambiente físico e social. In Santana P (ed.) A Cidade e a saúde. Almedina, Coimbra: 147-154.

Seeland K, Duberdorfer S, Hansmann R (2009) Making friends in Zurich's urban forests and parks: the role of public green space for social inclusion of youths from different cultures. Forest Policy and Economics, 11(1): 10-17.

Taylor A, Kuo f, Sullivan W (2001) Coping with ADD. The surprising connection to green play settings. Environment and Behaviour, 33(1): 54-77.

Thorsson S, Lindqvist M, Lindqvist S (2004) Thermal bioclimatic conditions and patterns of behaviour in an urban park in Göteborg, Sweden. International Journal of Biometeorology, 48: 149-156.

Tzoulas K, Korpela K, Yli-Pelkonen V, Kazmierczak A, Niemela J, James P (2007) Promoting ecosystem and human health in urban areas using green infrastructure: a literature review. Landscape Urban Planning, 81(3): 167-178.

Ulrich R (1984) View through a window may influence recovery from surgery. Science, 224: 42-421.

Van Herzele A, Wiedemann T (2003) A monitoring tool for the provision of accessible and attractive urban green spaces. Landscape Urban Planning, 63: 109-126.

Vasconcelos J, Vieira R (2007) Conforto bioclimático da Amadora. Contributo para o planeamento saudável. In Santana P (ed.) A Cidade e a saúde. Almedina, Coimbra: 147-154.

Wang X J (2009) Analysis of problems in urban green space system planning in China. Journal of Forestry Research, 20(1): 79-82.

Whitford V, Ennos A R, Handley J F (2001) City form and natural process - indicators for the ecological performance of urban areas and their application to Merseyside, UK. Landscape and Urban Planning, 57(2): 91-103. 
i Segundo a DGOTDU, i) os espaços verdes adjacentes à habitação (de pequena dimensão) devem localizar-se, no máximo, a 100 metros das áreas de residência; ii) os EVU de média dimensão devem localizar-se a menos de 400 metros; e iii) os EVU de maior dimensão, correspondendo a parques urbanos, devem ter uma acessibilidade igual ou inferior a 800 metros.

ii Neste número não se encontram contabilizados os alunos inscritos no ensino privado ou politécnico (caso de Coimbra).

iii O Plano Director Municipal de Coimbra (1994), refere que os espaços verdes «são áreas ou conjuntos de áreas com dimensão para assumirem uma categoria de uso no sistema urbano, caracterizadas pela elevada expressão do seu coberto vegetal e por um valor primordial na composição paisagística e que contribuem de forma significativa, como elementos de recreio e lazer, de protecção, e de composição paisagística para a qualidade do meio ambiente» (artigo $39^{\circ}$ ). No caso de Castela e Leão o Regulamento de Urbanismo (2009) define as zonas verdes como superfícies dentro dos espaços livres públicos, especificamente destinadas à plantação de espécies vegetais.

iv Em Portugal a Portaria n. ${ }^{\circ}$ 216-B/2008, de 3 de Março, define que, em operações de loteamento os espaços verdes junto a habitações colectivas devem ter um dimensionamento mínimo de $28 \mathrm{~m}^{2}$ por cada $120 \mathrm{~m}^{2}$ de área construída habitada. No entanto, o regulamento municipal de Coimbra definiu, para a mesma área, um dimensionamento de $27 \mathrm{~m}^{2}$ e, no caso de operações de loteamento, de $24 \mathrm{~m}^{2}$. No caso de Castela e Leão o RUCYL indica em Planes Geral uma extensão de $5 \mathrm{~m}^{2} / \mathrm{hab}$ (artigo 83) e um tamanho mínimo de $500 \mathrm{~m}^{2}$ nos Planes Parciales, dimensão vinculada ao total da superfície construível em cada novo bairro, evitando a sua aparição em zonas residuais da construção (artigo 105).

v Segundo os metadados do INE, a subsecção estatística é a unidade territorial que identifica a mais pequena área homogénea de construção ou não, existente dentro da secção estatística. Corresponde ao bairro nas áreas urbanas.

vi No total, o PDM de Coimbra classificou em 1994 na cidade como espaço verde urbano de uso público, existente e proposto, 298 ha. No entanto, apenas 148 ha existem actualmente enquanto espaço verde e só 105 ha são passíveis de utilização pública e em segurança. Neste estudo apenas são considerados os espaços verdes urbanos com manutenção pelos Serviços da Câmara Municipal de Coimbra.

vii De acordo com um dos dois critérios: a menos de $400 \mathrm{~m}$ dos EVU com dimensão inferior a 10ha ou a menos de 800 metros de EVU de dimensão superior a 09 ha.

viii A cidade de Amsterdão possui 761262 residentes (2009) e uma densidade de 4439 residentes por $\mathrm{km}^{2}$. Tem 28 parques espaços verdes urbanos e $35 \mathrm{~m}^{2}$ de espaço verde per capita (Chiesura, 2004). 